\title{
Discussion on University's Literature Resources Construction Based on the Key Subjects
}

\author{
Maoli Xu \\ library, \\ JiLin Agricultural University, \\ Changchun, China \\ Email: 473352805@qq.com
}

\begin{abstract}
University's literature resources construction based on the key subjects is an important part of the construction of the key subjects. Based on expounding the relationship between the development of university library and the construction of the key subjects, this paper puts forward some important measures for university library[()strengthen the construction of literature sources for the key subjects.
\end{abstract}

Keywords-university library; key subject; construction of literature resources

\section{INTRODUCTION}

As an important scientific research base, Colleges and universities has significant subject characteristics and disciplines advantage. In order to cater to the needs of continuous development and progress of the various disciplines in the information society which is characterized by knowledge dissemination and utilization, university library, as a literature resource base, its service orientation gradually changes from resources construction to subject service, and its resources construction is connected with key disciplines more and more. Construction of special resources provided resource base for the construction of key disciplines, and construction of key disciplines promotes and constrains the level of construction of special resources. At this time, university library should rely on the advantage of its key disciplines, combined with its resource base and the Library and Information professional advantage, builds special resources based on key disciplines. Comprehensively collect all kinds of information in subject areas, strengthen the integration and consolidation of information resources, achieve academic resource navigation and conduct in-depth knowledge mining, build the resources security system which has a distinct discipline characteristic.

\section{ANALYSIS OF RELATIONSHIP BETWEEN INFORMATION RESOURCES CONSTRUCTION AND KEY DiSCIPLINE CONSTRUCTION}

Key discipline construction is a key link for college discipline construction. It is one of basic projects of college connotation construction, a long-term systematic college project as well as the key for the survival and development. College library is an important base to provide information protection over the discipline construction. Information resource construction provides the necessary resource support for key disciplines, which in turn the development of key disciplines promotes the information resources construction. They complement each other and promote each other ${ }^{[1]}$.

\section{A. Connotation of Key Discipline Information Resources Construction}

Key discipline information resource refers to the collection required by the library application research and theoretical researches within a range of key disciplines or professional range. It can be able to support key teachers, so the researchers can conduct scientific research and provide teaching counseling, and meet the overall needs of the subject topic. On the one hand, it has a guiding role that guides the professional learning direction of students, help teaching and research personnel understand the frontier developments of the subject for convenient topic selection and determines the main direction; on the other hand, it can provide existing teaching and research information to teaching and research personnel, accelerate the research process, avoid repeated works and improve efficiency ${ }^{[2]}$. It should be said that the whole process of college teaching and research progress and training of high-level personnel require the supports from the library information resources, and the information resource quantity and quality provided by college libraries will play a very important role in the key discipline construction.

\section{B. Information Resource Construction is the guarantee of key discipline construction}

Information resource for key disciplines is the most basic element for college libraries as well as the fundamentals and guarantee of key discipline construction services. The quality of college library information resource directly affects the key discipline construction, the training of high-level talents and the development of college level. Therefore, the information resource construction of the college library must be closely associated with the development of college key disciplines, and provide the necessary support and guarantee for the key discipline construction. 


\section{Development of key discipline construction promotes the information resource construction}

Key discipline construction has rich connotation, distinctive features and specific laws. With the rapid development of science and technology, various disciplines present new development trends, various disciplines intersect with each other, a discipline continues to deep in a field, and develops toward the overall direction of integrated and intersecting development. Key discipline construction aims to improve the college teaching and research level, enhance the continued training of high-level talents, and increase the college competitiveness. After a long time of construction and development, colleges have formed key disciplines representing the teaching, scientific research advantages and characteristics, became the cradle of training high-level, high-quality talents, and became an important base for the creation of high-level scientific research achievements ${ }^{[3]}$. Development of key discipline construction inevitably requires that the information resource construction shall be developed accordingly, and it points out the direction for the information resource construction with the orientation of key disciplines and promotes the college library information resource construction.

\section{LIBRARY INFORMATION RESOURCE CONSTRUCTION STRATEGY BASED ON KEY DISCIPLINES}

\section{A. Establish the resource construction evaluation mechanism based on key disciplines}

The proposal of college key disciplines points out the direction for the center of library information resources construction. However, the library shall carefully think and study how to efficiently build the high-quality information resource system that meets the basic development requirements of key disciplines within a short period for the key discipline construction. Establishment of discipline-based information resource construction evaluation mechanism can enable the key discipline information construction of library to be carried out under the system guarantee, avoid interference from personal factors of constructors, and ensure the high quality of key information resource construction. The evaluation mechanism consists of three parts. The first is the basic system of key discipline resource construction, including the resource evaluation methods, procedures and processes; the second is allocation and use of construction funds, including core resources and the capital proportion of general resources; the third is recruitment and training of resource construction personnel. In short, a good resource evaluation mechanism is the key to guarantee the quality of key discipline resource construction ${ }^{[4]}$. Only under the specification, the library can ensure the quality of key discipline resource construction, further carry out all support services on this basis for the key disciplines, and promote the rapid development of college key discipline construction.

\section{B. Improve the quality of resource construction personnel}

Improvement of the quality of resource construction personnel is the key to further strengthen the quality of key discipline resource construction. Libraries should actively carry out the educational training works of resource constructors for key disciplines, update and improve the professional quality of construction personnel. Specific measures are as below. First, improve the resource construction business literacy of personnel, all key discipline resource construction personnel should work after accepting relevant education and training. Secondly, carry on professional training for key disciplines, actively cooperate with the departments of key disciplines, ask them to add the relevant subject knowledge for the resource construction personnel of libraries. Thirdly, improve the foreign language skills of resource construction personnel. Foreign language is a window to see the world, and this ability plays an important role in the construction of high quality foreign language resource. Fourthly, improve the information technology of construction personnel, good information skill is a technical assurance for construction personnel to timely find and accurately collect the urgently needed information resources of key disciplines. Therefore, only by greatly improving the quality of resource construction personnel can efficiently build the high-quality information resource system that meets the needs of key discipline construction, and always maintain clear and accurate grasping of the direction of college key discipline construction.

\section{Coordinate the resource relationship between key disciplines and general disciplines}

In the college discipline construction system, relationship between key disciplines and general disciplines is the relationship between points and planes. Key discipline itself develops and grows from the general disciplines. Therefore, during the information resource construction of library, in spite of the distinction, do not go to extremes. While first meeting the needs of key discipline resource construction, timely consider the actual needs of other general disciplines. More importantly, while the library meets the resource needs of other general disciplines, support the resource needs of general disciplines with major potentials in a more long-term vision. In such a way, based on the resource construction of key disciplines, the library can have current construction focus, and have the guarantee supports of forward-looking vision of development.

\section{Intensify efforts in digital resource construction}

With the digital and network development of modern 
social information resources, digital information resource has become the most important open resource in current society. This resource does not occupy the physical space, can be provided to the multiple people, so it has developed into the most promising strategic library resource. In addition, current social traditional digital and network transformation makes the social sharing of traditional resources become a reality, the library no longer needs to put too much effort for the construction of traditional resources, and it may be achieved by joining the sharing alliance. It is obvious that with the further application of modern social information technology, digital resources will eventually become the most core information resource of library. In the information resource construction based on key disciplines carried out by college libraries, digital information resource must become the most important construction focus, which not only reduces the cumbersome resource acquisition, but also enable the library to quickly build the resource system to support key disciplines in the shortest time. It is favorable for the construction of college key disciplines and can greatly accelerate the development pace of college key disciplines ${ }^{[5]}$.

\section{E. Take the path of common construction and shared development}

In recent years, the sharp rise in the price of traditional information resources makes the library resource construction face enormous financial pressure. With the limited funds, how to optimize the information resource construction is a long-term difficult problem for the library development. Libraries should follow a common construction and shared development, build the alliance of information resources, and optimize the information resource construction by using the alliance inter-library borrowing or transfer of resources. Under the real conditions, libraries make up the deficiencies of talents, capital and resources, and it is the most effective way to meet the information needs of the user. It not only makes the library quickly build the resource guarantee system to support the development of key disciplines, but also plays the huge inter-library reference and counseling services, which will greatly enhance the service level and efficiency of library itself.

\section{CONCLUSION}

Information resource system construction is an inevitable choice for the college library service discipline construction as well as an important topic for college libraries to face in the new situation. College libraries should make full use of resource advantages, integrate the new technologies into the knowledge service system, reform the service model, improve the service quality, play a greater role in promoting the college teaching and research, and finally make the library become the hub and core of college key discipline construction.

\section{REFERENCES}

[1] ZhongGuoqin. Discussion on University's Literature Resources Construction Based on the Key Subjects[J].Sci-tech Information Development \& Economy,2012(7):15-17.

[2] Liang Aidong, Tan Yan. Research on the Library's Information Resources Construction Strategy Based on the Key Disciplines[J].Sci-tech Information Development \& Economy,2015(1):68-70

[3] GuoYuqiang. Information Resources Construction and Key Subject Literature Guarantee in University Libraries[J]. Academic Library and Information Service,2009(2):5-7.

[4] Wu Youmei, Huang Chunjuan, Ma Jiujie. A Study of the Document Resources Construction for Teaching Guarantee of Academic Library Based Document Utilization Ratio[J].Library,2013(2):73-74.

[5] Gao Junfang. Accelerating Literature Resources Constructing of Key Subject to University Using Document Delivery Service[J]. Journal of Modern Information, 2009(4):98-102. 